\title{
Study of Phycocyanin Production from Spirulina platensis Under Different Light Spectra
}

\author{
Alfredo Walter, Júlio Cesar de Carvalho*, Vanete Thomaz Soccol, Ana Bárbara Bisinella \\ de Faria, Vanessa Ghiggi and Carlos Ricardo Soccol \\ Departamento de Engenharia de Bioprocessos e Biotecnologia; Universidade Federal do Paraná; Curitiba - PR - \\ Brasil
}

\begin{abstract}
The aim of this work was to investigate the production of phycocyanin by Spirulina platensis under different spectra of light. The dependent variables evaluated were the amount of phycocyanin obtained and its purity, demonstrating that there might be a restructuring of phycobilisomes, especially when the culture was subjected to red light, which increased the purity level up to $33 \%$ with a reduction of $16 \%$ in phycocyanin content, but with higher photosynthetic efficiency compared to natural light.
\end{abstract}

Key words: Spirulina; phycocyanin, phycobilisome, pigment, spectrum, chromatic acclimation

\section{INTRODUCTION}

The algae that live in habitats under high solar irradiation have accessory pigments that protect them from radiation damage and also from oxidation, due to the conjugated double bonds present in the chromophores. It is this composition and arrangement of accessory pigments that give to algae a wide variety of colors and for some groups, their usual names such as "brown algae", "red algae", "golden algae" and "green algae" (Gualtieri and Barsanti, 2006; Lee, 2001). Cyanobacteria and other algae have a wide range of pigmented compounds, including carotenoids, chlorophyll and phycobiliproteins, which consist of dimers with two subunits $(a$ and $b)$ of pigmented polypeptides (Sarada, et al., 1999). Some species of microalgae, such as Spirulina, stand out in this context by presenting biomass with excellent nutritional characteristics. Besides the high protein content, there are several compounds and natural pigments with functional properties. Among the phycobiliproteins derived from Spirulina, phycoerythrin (PE) and allophycocyanin (AP) can be found in small amounts, but the most abundant is phycocyanin (PC), a brilliant blue pigment that, depending on its purity, finds different important applications (Becker and Ventkataraman, 1984; Berg, et al, 2002; Gualtieri and Barsanti, 2006; Silva, 2008). The presence of antioxidant compounds such as phenolic compounds and phycocyanin, and polyunsaturated fatty acids in the microalga Spirulina can be the cause of its property of serum lipids levels reduction and HDL-cholesterol increasing (Colla, et al., 2007b, Colla, et al., 2008).

The primary potential of these molecules seems to be their use as natural dyes, but a growing number

*Author for correspondence: jccarvalho@ufpr.br 
of studies have shown the properties related to health benefits and wide pharmaceutical application. In addition, phycobiliproteins are widely used in laboratory tests and immunological assays, due to their properties such as high fluorescence, good storage stability at temperatures between 4 and $10{ }^{\circ} \mathrm{C}$, isoelectric point (IP) close to 4.65 , making them easily linkable to antibodies and other proteins by conventional techniques without changing its spectral characteristics, have high molar absorbance coefficient and emission, oligomeric stability and high photo-stability (Prozyme, 2009). The commercial value of phycocyanin is directly related to its purity degree, which can vary between a minimum rate to be considered food grade (approximate value of $\$ 0.13 \mathrm{mg}^{-1}$ ) to the highest level of purity (product considered of analytical grade), where the product can be sold up to $\$ 25 \mathrm{mg}^{-1}$. This shows that highly purified phycocyanin may reach a high commercial value. However, improving the production, extraction and purification of phycocyanin, as well as developing more stable formulations, may ensure an even broader application (Borowitzka, 1999; Derner, 2006; Spolaore, et al., 2006; Eriksen, 2008; Prozyme, 2009).

The culturing conditions can influence decisively the growth phases of Spirulina, causing changes in its composition and increasing or decreasing the proportion of phycobiliproteins, including phycocyanin. Studies have indicated that the quantities of phenolics could also be increased by altering the culture conditions, suggesting that it was possible to increase the antioxidant potential of $S$. platensis biomass for use as a nutritional supplement (Colla, et al., 2007).

Most groups of algae are obligatory photoautotrophs, in other words, they are entirely dependent on their photosynthetic apparatus for their metabolic needs, using sunlight as energy source and carbon dioxide $\left(\mathrm{CO}_{2}\right)$ as carbon source to produce the carbohydrates and ATP (Gualtieri and Barsanti, 2006 and Lee, 2008). Moreover, the culture media have a key role in the optimal development of microalgae. Sea water, nutrients (C, N, O, H, P, and $\mathrm{Ca}, \mathrm{S}, \mathrm{Mg}$ and $\mathrm{K}$ ), trace metals (typically $\mathrm{Fe}, \mathrm{Mn}, \mathrm{Cu}$, Mo and $\mathrm{Co}$ ) as well as chelators, vitamins and soil extract should be added in appropriate proportions. The dependence on light as energy source is an essential aspect in the design of photobioreactors. Eriksen (2008) reported that high light intensity was the main characteristic of any photosynthetic system, and the correct distribution of light along the photobioreactor should be observed. On the other side, too much light may cause photoinhibition (limited growth) and hence low conversion of light energy into biomass, i.e., low photosynthetic efficiency (PE) (Gualtieri and Barsanti, 2006; Wang, et al, 2007). The chromatic acclimation process allows the cells of cyanobacteria to alter its light absorption characteristics in order to regulate photosynthesis according to light availability in different environments. As a consequence of this phenomenon, the pigment which absorbs the incident wavelengths of light most strongly becomes predominant (Bennett and Bogorad, 1973; Gualtieri and Barsanti, 2006; Wang, et al, 2007).

The objective of this study was to verify the intensity with which this process took place in Spirulina, and the effects on phycocyanin synthesized, in terms of quality and quantity, which might influence the overall production process.

\section{MATERIALS AND METHODS}

\section{Microorganism}

The microorganism used was Spirulina platensis, strains Paracas and LEB52. These strains were maintained by successive cultures in Zarrouk medium (ZARROUK, 1966).

\section{Culture medium}

For all the cultivations the Zarrouk medium was used (Zarrouk, 1966), diluted to 20\% (Reinehr, 2001). The solutions with the respective salts were sterilized separately by autoclaving at $121^{\circ} \mathrm{C}$, for 15 minutes and mixed afterwards to achieve the final medium.

\section{Culture technology and the conditions for chromatic acclimation}

This study established different conditions that could generate complementary chromatic acclimation processes, including: (A) five photobioreactors $(200 \mathrm{~mL}$ cell culture flasks) filled with $150 \mathrm{~mL}$ of $S$. platensis LEB052 cultures, installed in a room (temperature $30 \pm 2.0^{\circ} \mathrm{C}$ and under artificial lighting: white $20 \mathrm{~W}$ fluorescent lamps with light intensity of 0,8 klux). Four of these photobioreactors were covered with commercial colored filters (red, yellow, blue and 
green); (B) four photobioreactors (50 L tanks) with initial volumes of $20 \mathrm{~L}$ of $S$. platensis Paracas cultures, installed in a greenhouse - more influenced by climatic instability - with an average temperature of $25.3^{\circ} \mathrm{C}$ during the experiment, with forced aeration (bubbling air at $600 \mathrm{~mL} \cdot \mathrm{min}^{-1}$ ) by a diaphragm pump. Three of these tanks were covered with colored filters (red, yellow and blue). The light intensity under these different filters was also measured; (C) photobioreactors $(200 \mathrm{~mL}$ cell culture flasks) filled with initial volume of $150 \mathrm{~mL}$ of $S$. platensis LEB052 cultures and covered with the same color filters, though submitted to controlled environmental conditions (temperature $30 \pm 1.0^{\circ} \mathrm{C}$ ), with agitation $(120 \mathrm{rpm})$ and $1.0 \mathrm{klux}$ of light intensity (Graham and Wilcox, 2000; The Kehoe Laboratory, 2009). The light quality (spectrum) was manipulated with filters with light/dark cycles (12:12 $\mathrm{h}$ in A condition, and natural cycles (close to $12: 12 \mathrm{~h}$, but variable light intensity) in B and C conditions. The $\mathrm{pH}$ of all the cultures was maintained in the range between 8.5 to 9.5, characteristic of the Zarrouk medium.

\section{Biomass production}

The algal growth was evaluated by measuring in triplicate the dry weight obtained after stabilization at $105{ }^{\circ} \mathrm{C}$ and using it to calibrate an absorbance curve (at $670 \mathrm{~nm}$ ) of diluted samples. The specific growth rate $(\mu)\left(d^{-1}\right)$ was related to the experimental values of cell concentration versus time (d) as showed in equation 1 (Silva, 2008):

$$
\mu=\frac{1}{X} \cdot \frac{d X}{d t}
$$

Where: $\mu=$ specitic growth rate $\left(\mathrm{d}^{-1}\right) ; \mathrm{t}=$ time for growing (days) and $\mathrm{X}=$ cellular concentration (g.L $\left.\mathrm{L}^{-1}\right)$.

Productivity is the ratio between the difference in cell concentration in a given period and the period itself, as shown in equation 2:

$$
P=\left(X_{i}-X_{0}\right) / t_{i}
$$

Where: $\mathrm{P}=$ productivity $\left(\mathrm{mg} \cdot \mathrm{L}^{-1}\right.$ day $\left.^{-1}\right) ; \mathrm{X}_{0}=$ initial cell concentration $\left(\mathrm{mg} . \mathrm{L}^{-1}\right) ; \mathrm{X}_{\mathrm{i}}=$ cell concentration at time $\mathrm{i}\left(\mathrm{mg} \cdot \mathrm{L}^{-1}\right)$ and $\mathrm{t}_{\mathrm{i}}=$ time range (days) between $\mathrm{X}_{0}$ and $\mathrm{X}_{\mathrm{i}}$.

\section{Extraction and purification of phycocyanin}

The phycocyanin was extracted through a combination of two procedures: addition of $0.1 \mathrm{M}$ phosphate buffer ( $\mathrm{pH}$ 7.0), followed by five successive freezing and thawing cycles of the biomass in order to disrupt the cell walls and consequently to isolate the phycocyanin. The evaluation of the extraction, based on the concentration of phycocyanin, was set by Equation 3, deduced by Bennett and Bogorad (1973):

$$
F C=\frac{\left(A_{620}-0,474\left(A_{662}\right)\right)}{5,34}
$$

Where: $\mathrm{FC}=$ concentration of phycocyanin (in $\left.\mathrm{mg} \times \mathrm{mL}^{-1}\right) ; \mathrm{Abs}_{620}=$ absorbance of the sample at $620 \mathrm{~nm}$ and $\mathrm{Abs}_{652}=$ absorbance at $652 \mathrm{~nm}$.

The purity of phycocyanin was determined by the ratio between the absorbance of a sample of pigment at $620 \mathrm{~nm}\left(\mathrm{~A}_{620}\right)$, proportional to the amount of pigment, and that at $280 \mathrm{~nm}\left(\mathrm{~A}_{280}\right)$, proportional to some amino acids present in the proteins in the solution. The samples of phycocyanin with an $\mathrm{A}_{620} / \mathrm{A}_{280}$ ratio greater than 0.7 are considered as food grade. The samples with $\mathrm{A}_{620} / \mathrm{A}_{280}$ ratio of 3.9 are considered reactive grade, while values above 4.0 are considered to be of analytical grade. The precipitation with saturated solution of ammonium sulfate $\left(\left(\mathrm{NH}_{4}\right)_{2} \mathrm{SO}_{4}\right)$, was used in order to obtain the phycocyanin enriched solutions (Eriksen, 2008; Silva, 2008; Sarada et al., 1999 and Silveira, 2007).

\section{RESULTS AND DISCUSSION}

The kinetics of S. platensis growth was performed in order to evaluate the capacity of cellular growth of microalgae in different culture conditions. After twenty days of cultivation, the standard culture (without using a filter) achieved a cellular concentration of $0.6 \mathrm{mg} \cdot \mathrm{ml}^{-1}$ in condition A, $0.9 \mathrm{mg} \cdot \mathrm{ml}^{-1}$ in condition $\mathrm{B}$ (with forced aeration) and $0.6 \mathrm{mg} \cdot \mathrm{ml}^{-1}$ in condition C. It was possible to make an analogy with the work of Monteiro et al. (2010), which demonstrated that a system with artificial and continuous aeration could reduce labor hours and could be a more effective method for improving the process economy. The cell concentration was measured at the same period. When the light filters were used, biomass was lower in all the cases, but with some variations due to the specific color used in the filter, as shown in Figures 1, 2 and 3 that represented the cell growth for conditions A, B and C, respectively. As shown 
in those figures, the growth was influenced by the filter and all the conditions showed that Spirulina had the same growth pattern when submitted to the same filters. The average productivity related to each filter and condition is depicted in Table 1:

Table 1 - Average biomass productivity $\left(\mathrm{g} \cdot \mathrm{L}^{-1} \cdot \mathrm{day}^{-1}\right)$.

\begin{tabular}{cccc}
\hline & \multicolumn{3}{c}{ Condition } \\
\hline Reactor & A & B & C \\
\hline Standard & 0,03 & 0,059 & 0,018 \\
Yellow & 0,025 & 0,037 & 0,015 \\
Red & 0,021 & 0,035 & 0,011 \\
Green & 0,016 & - & 0,013 \\
Blue & 0,015 & 0,025 & 0,006 \\
\hline
\end{tabular}

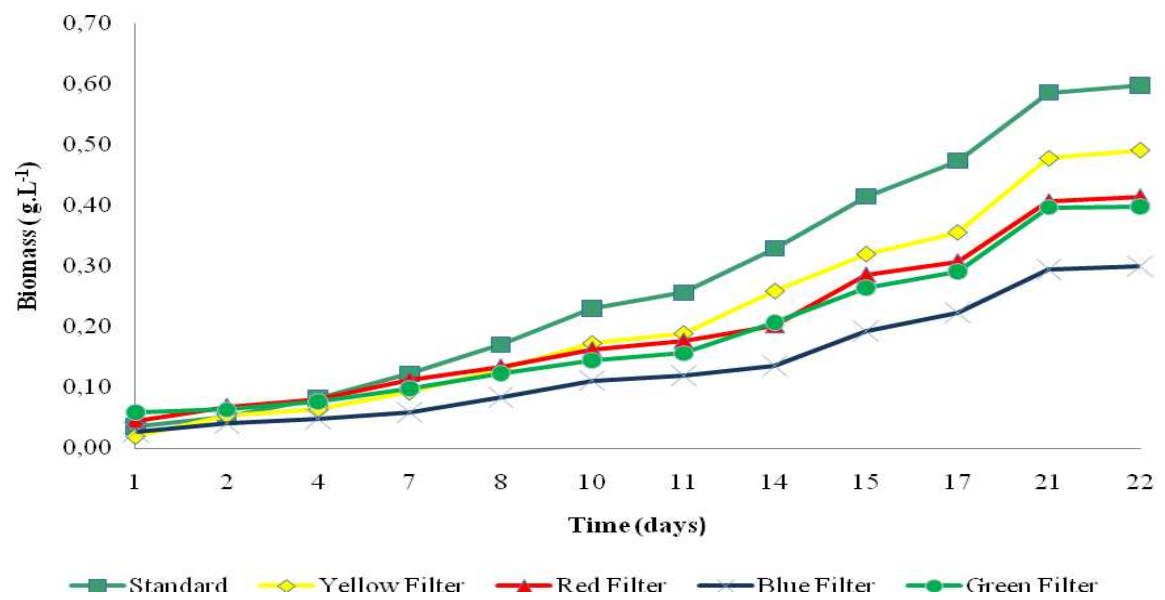

Figure 1 - Cell concentration and its relation with the filter tested (condition A).

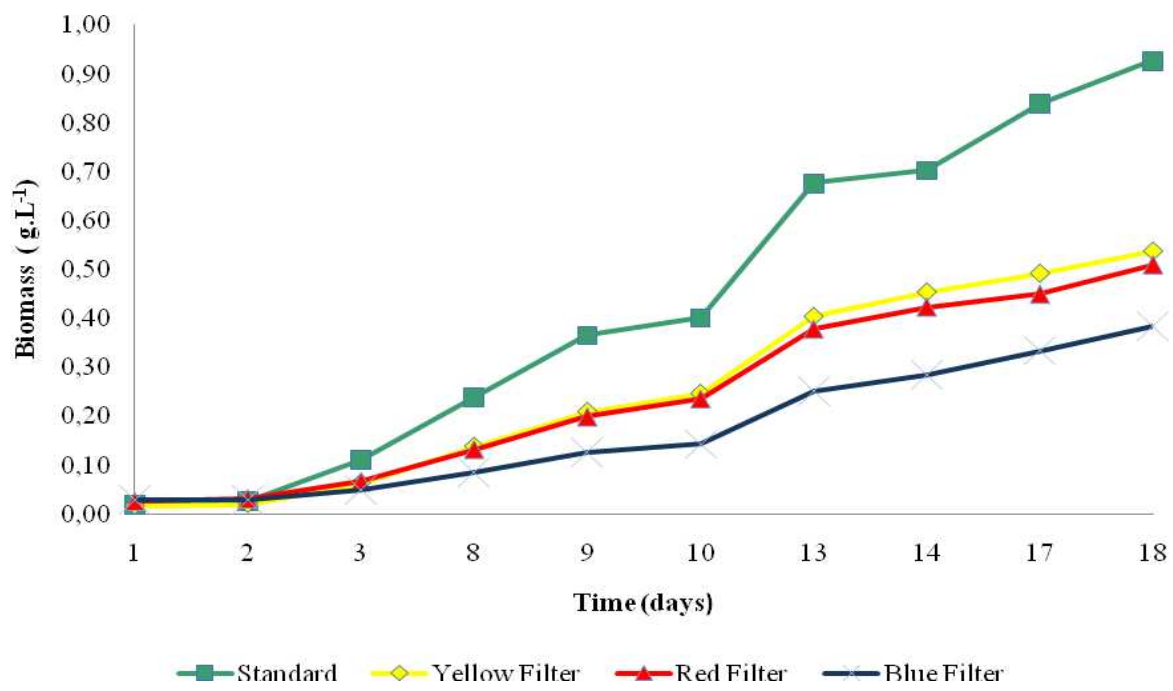

Figure 2 - Cell concentration and its relation with the filter tested (condition B). 


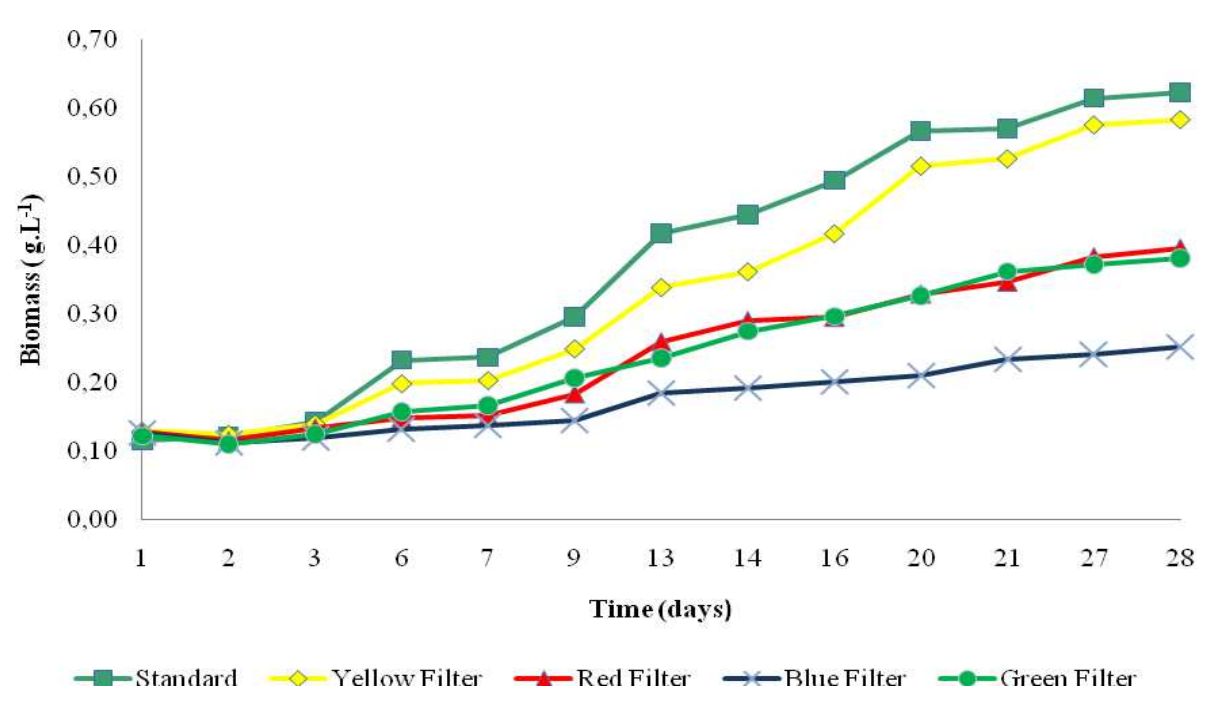

Figure 3 - Cell concentration and its relation with the filter tested (condition C).

Figure 4 shows the light spectrum of the different filters used, compared with the $S$. platensis absorption spectrum. Evidently the absorption was high throughout the visible spectrum, which showed the complementarity of chlorophylls (which absorb mainly blue and red light) and the blue pigment phycocyanin (which absorb mainly yellow and orange light), resulting in high absorbance in the overall spectrum. This characteristic mix of pigments of Spirulina, absorbs more incident light close to wavelengths $620 \mathrm{~nm}$ and $670 \mathrm{~nm}$, as usual for cyanobacteria (Chronakis, et al., 2000; Costa, et al., 2000 and 2002; Colla, et al., 2007a).

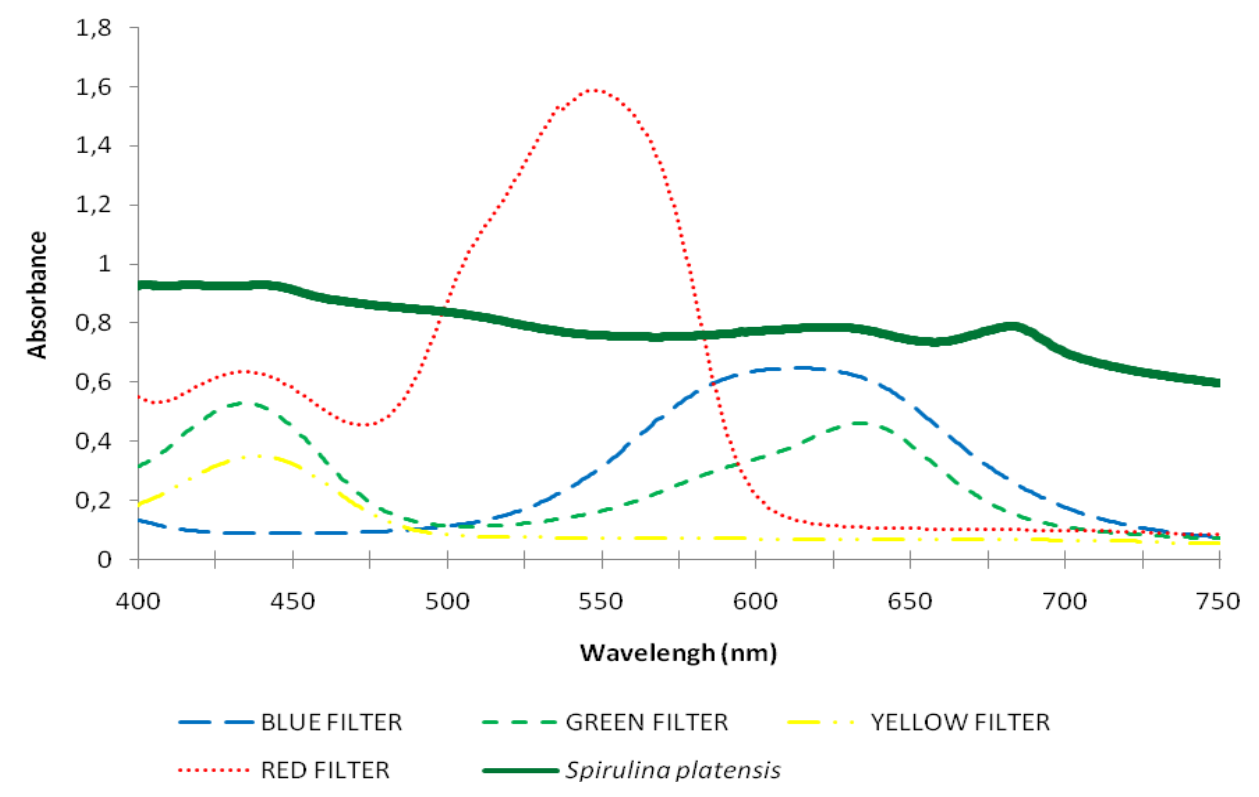

Figure 4 - Absorption spectrum of different filters used compared to the Spirulina platensis $(\mathrm{X}=1 \mathrm{~g} / \mathrm{L})$ spectrum. 
Table 2 shows the light intensity measured directly beneath each filter used. The extraction of phycocyanin was also studied to understand the relationship between the chromatic acclimation to the production of pigment under the growth conditions and the filter used. The results showed that the cell growth (shown in Figures 1, 2 and 3) was not proportional to light intensity when filters were used. Neither was phycocyanin production, which was higher when the red filtered light was used, an adaptation to the narrower range of light provided by the filter. Wang et al, (2007) studied the influences of light wavelength and intensity of various light-emitting diodes (LEDs) on $S$. platensis and found a high specific growth rate for red light and that the least efficiency in the conversion of photons was by blue light.

The results shown in Table 2 referred to the open photobioreactor, installed in a greenhouse, under the sunlight and constant aeration. Thus, energy consumption was restricted only to the aeration system and the use of a simple red light filter showed very interesting results to the system, improving the purity almost $30 \%$, while the amount of phycocyanin obtained was only $16 \%$ lower compared with the standard cultivation. It is noteworthy that qualitatively similar results were obtained with the cultures in the photobioreactors of controlled temperature conditions (conditions A and C); however, the cell growth and phycocyanin production was slightly lower, probably because of the use of artificial lighting (Reichert, et al., 2006).

Table 2 - Light intensity on each filter and the amount of phycocyanin produced in Condition B.

\begin{tabular}{cccc}
\hline Reactor & Luminous intensity $(\mathbf{l u x})$ & Phycocyanin $\left(\mathbf{m g} \times \mathbf{m} \mathbf{L L}^{\mathbf{- 1}}\right)$ & Purity grade of phycocyanin \\
\hline Standard & 1700 & 0.237 & 0.8 \\
Red & 800 & 0.198 & 1.1 \\
Yellow & 1300 & 0.174 & 0.7 \\
Blue & 1000 & 0.144 & 0.8 \\
\hline
\end{tabular}

Figure 5 depicts the chromatic acclimation process with Spirulina, and the enrichment of the antenna in phycocyanin under red light.

The precipitation of phycocyanin with the saturated solution of ammonium sulfate is considered a primary purification step. This method promotes the precipitation of part of the other proteins, concentrating the phycocyanin and purifying it to the levels permissible for some uses.

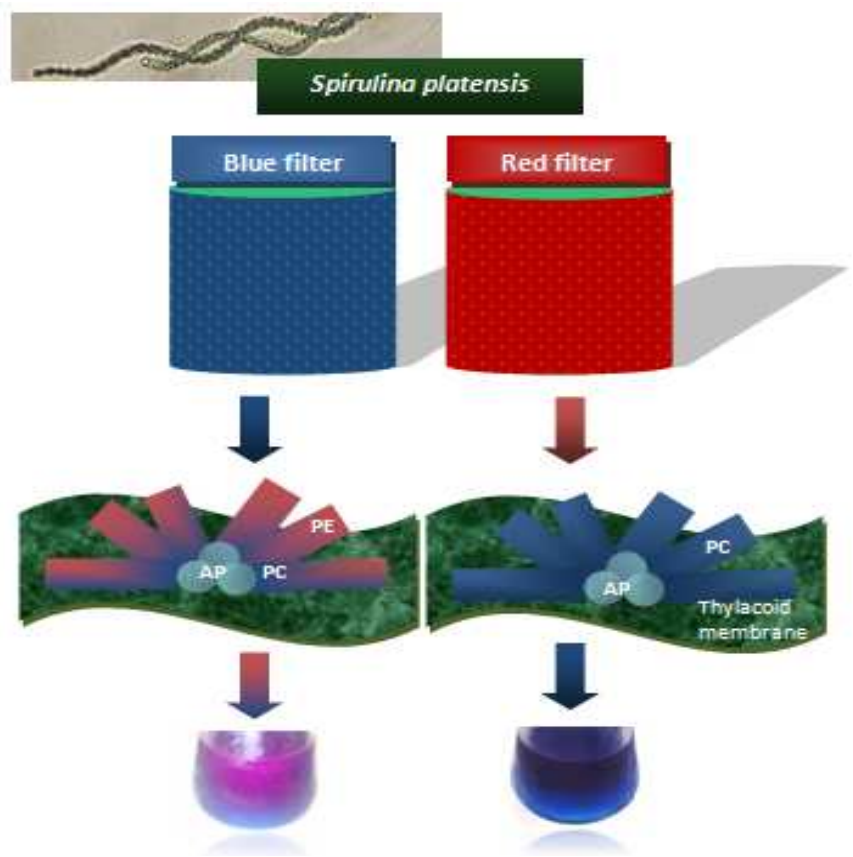

Figure 5 - Chromatic acclimation process with tested cultures of Spirulina platensis. 
It was observed that the purity of phycocyanin obtained was low as a result of the purification technique used; however, sufficient for a product with food grade (after desalination). Other purification techniques based on chromatography, for example, can provide a higher degree of purity, if needed.

\section{CONCLUSION}

The results demonstrated the influence of chromatic acclimation of $S$. platensis and its consequences in phycocyanin production. The photobioreactors where the light quality was manipulated with a filter transmitting red light showed a good production of phycocyanin, with higher purity. This represented a simple way to increase the phycocyanin purity. Another important aspect to be considered and worthy of further studies is related to the reduction in lighting energy expenditure and consequent reduction in the production costs, as new cultures with extra artificial lighting or filters that transmit light in the red spectrum might present higher purity and higher photosynthetic efficiency.

The fact that the absorption spectrum of the different filters used do not provide well defined emission peaks suggests that further studies using light sources with narrower emission spectrum may provide even better control of the composition of Spirulina.

\section{ACKNOWLEDGEMENTS}

The authors wish to thank Fundação Araucária FA and Conselho Nacional de Desenvolvimento Científico e Tecnológico - CNPq for their support to this research.

\section{REFERENCES}

Bennet, A.; Bogorad, L. (1973), Complementary Chromatic Adaptation in a Filamentous Blue-green Alga. The J. of Cell Biol., 58, 419-435.

Becker, E. W.; Ventkataraman, L. V. (1984). Production and utilization of the blue-green algae Spirulina in India. Biomass, 4, n. 2, 105-125.

Berg, J. M., Tymoczko, J. L., Stryer, L. (2002), Biochemistry. 5th Ed. New York: W H Freeman
Borowitzka, M. A. (1999) Commercial production of microalgae_ponds, tanks, tubes and fermenters. $J$. Biotechnol., 70, 313-321

Chronakis, I. S.; Galatanu, A. N.; Nylander, T.; Lindmann, B. (2000), The behavior of protein preparations from blue-green algae (Spirulina platensis strain Pacifica) at the air/water interface. Colloid Surface A. 173, 181-192.

Colla, L. M.; Reinehr, C. O.; Reichert, C.; Costa, J. A. V. (2007a), Production of biomass and nutraceutical compounds by Spirulina platensis under different temperature and nitrogen regimes. Biores. Technol. 98, 1489-1493.

Colla, L. M., Furlong, E. B., Costa, J. A. V. (2007b), Antioxidant Properties of Spirulina (Arthospira) platensis Cultivated Under Different Temperatures and Nitrogen Regimes. Braz. Arch. Biol. Technol. 50, n. 1, 161-167.

Colla, L. M., Muccillo-Baisch, A. L., Costa, J. A. V. (2008), Spirulina platensis Effects on the Levels of Total Cholesterol, HDL and Triacylglycerols in Rabbits Fed with a Hypercholesterolemic Diet. Braz. Arch. Biol. Technol. 51 n.2, 405-411.

Costa, J. A. V.; Linde, G. A.; Atala, D. I. P.; Mibielli, G. M.; Krüger, R. T. (2000), Modeling of growth conditions for cyanobacterium Spirulina platensis in microcosms. World J. Microbiol. Biotechnol. 16, 1518.

Costa, J. A. V.; Colla, L. M.; Filho, P. D.; Kabke, K.; Weber, A. (2002), Modeling of Spirulina platensis growth in fresh water using response surface methodology. World J. Microbiol. Biotechnol, 18, 603-607.

Derner, R. B. (2006), Efeito de fontes de carbono no crescimento e na composição bioquímica das microalgas Chaetoceros muellei e Thalassiosira fluviatilis, com ênfase no teor de ácidos graxos poliinsaturados. PhD Thesis, Universidade Federal de Santa Catarina, Florianópolis, Santa Catarina, Brasil.

Eriksen, N. T. (2008), Production of phycocyanin-a pigment with applications in biology, biotechnology, foods and medicine. Appl. Microbiol. Biotechnol., 80, $1-14$.

Graham, L. E. and L. W. Wilcox (2000), Algae. Prentice Hall: Upper Saddle River, N.J. 640 pp.

Gualtieri, P.; Barsanti, L. (2006), Algae: anatomy, biochemistry, and biotechnology. CRC Press, Taylor and Francis Group. 301 p. il.

Lee, YK. (2001), Microalgal mass culture systems and methods: Their limitation and potential. J. of Appl. Phycol. 13, 307-315.

Lee, R. E. (2008), Phycology. $4^{\text {th }}$ edition. Colorado State University, USA. 561 p. il.

Monteiro, M. P. da C. Luchese, R. H. , Absher, T. M. (2010). Effect of Three Different Types of Culture Conditions on Spirulina maxima Growth. Braz. Arch. Biol. Technol. 53 n.2, 369-373. 
Prozyme (2009). C-Phycocyanin (Specifications). Products. [homepage on the Internet]. USA, Available from: http://www.prozyme.com.

Reichert, C. C.; Reinehr, C. O.; Costa J. A. V. (2006), Semicontinuous cultivation of the cyanobacterium Spirulina platensis in a closed photobioreactor. Braz. J. Chem. Eng., 23, n. 01, 23-28.

Reinehr, C. O. (2001), Estudo do cultivo semicontínuo de microalga Spirulina platensis utilizando água da lagoa Mangueira. MSc Dissertation. Universidade Federal do Rio Grande, Rio Grande, Brasil.

Sarada, R.; Pillai, M. G.; Ravishankar, G. A. (1999), Phycocyanin from Spirulina sp: influence of processing of biomass on phycocyanin yield, analysis of efficacy of extraction methods and stability studies on phycocyanin. Proc. Bioc. 34, 795-801.

Silva, L. A. (2008), Estudo do Processo Biotecnológico de Produção, Extração e Recuperação do Pigmento Ficocianina da Spirulina platensis. MSc Dissertation. UFPR, Curitiba, Paraná, Brasil.

Silveira, S. T.; Burkert, J. F. M.; Costa, J. A. V.; Burkert, C. A. V.; Kalil, S. J. (2007), Optimization of phycocyanin extraction from Spirulina platensis using factorial design. Biores. Technol. 98, 16291634.
Spolaore, P., Cassan, C.J., Duran, E., Isambert, A., (2006), Commercial Applications of Microalgae. J. Biosci. Bioeng. 101, No.2, 87-96.

The Kehoe Laboratory (2009), Department of Biology at Indiana University Bloomington. Uncovering Mechanisms Regulating Red-Green Light Acclimation. [homepage on the Internet]. USA, Available from http://www.bio.indiana.edu/ $\sim$ kehoelab/research.html.

Wang C.-Y.; Fu, C.-C., Liu, Y.-C. (2007), Effects of using light-emitting diodes on the cultivation of Spirulina platensis. Biochem. Eng., 37, 21-25.

Zarrouk, C. (1966), Contribuition à létude d une cyanophycée: influence de divers facteurs physiques et chimiques sur la croissance et la photosynthèse de Spirulina maxima. PhD Thesis, Université Des Paris, Paris.

Received: April 05, 2010; Revised: September 03, 2010; Accepted: April 22, 2011. 